\title{
There is a correlation between histopathological findings of joint capsule and synovium, and postoperative clinical outcomes and treatment in patients with isolated type II superior labrum anterior posterior lesions
}

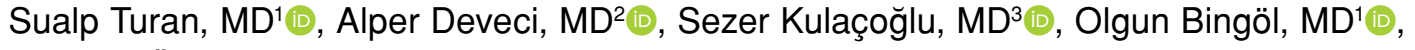 \\ Güzelali Özdemir, MD ${ }^{1}$ (0) \\ ${ }^{1}$ Department of Orthopedics and Traumatology, University of Health Sciences Ankara City Hospital, Ankara, Turkey \\ ${ }^{2}$ Department of Orthopedics and Traumatology, Ankara Private Ortadogu Hospital, Ankara, Turkey \\ ${ }^{3}$ Department of Pathology, University of Health Sciences Ankara City Hospital, Ankara, Turkey
}

Superior labrum anterior posterior (SLAP) lesion describes a tear of the superior labrum that extends from anterior to posterior. ${ }^{[1]}$ In type II SLAP lesions, superior labrum and biceps anchor are detached from the superior glenoid. ${ }^{[2]}$ Of the various subtypes, type II SLAP lesions remain as the most common type of SLAP lesions, comprising 55\% of all diagnosed lesions. ${ }^{[2]}$

There is still controversy in the management of SLAP lesions in the literature. Treatment options for type II SLAP lesions include nonoperative or operative treatment. ${ }^{[3]}$ Generally, nonoperative treatment is initially preferred in patients with

Received: July 07, 2020

Accepted: August 04, 2020

Published online: September 11, 2020

Correspondence: Sualp Turan, MD. SBÜ Ankara Şehir Hastanesi

Ortopedi ve Travmatoloji Kliniği, 06800 Çankaya, Ankara, Türkiye.

E-mail: sualptu@yahoo.com

Doi: 10.5606/ehc.2020.77899

Citation: Turan S, Deveci A, Kulaçoğlu S, Bingöl O, Özdemir G. There is a correlation between histopathological findings of joint capsule and synovium, and postoperative clinical outcomes and treatment in patients with isolated type II superior labrum anterior posterior lesions. Jt Dis Relat Surg 2020;31(3):440-448.

(02020 All right reserved by the Turkish Joint Diseases Foundation

This is an open access article under the terms of the Creative Commons Attribution-NonCommercial License, which permits use, distribution and reproduction in any medium, provided the original work is properly cited and is not used for commercial purposes (http://creativecommons.org/licenses/by-nc/4.0/).

\section{ABSTRACT}

Objectives: This study aims to histologically examine the joint capsule and synovium to determine the correlation between histopathological findings and postoperative clinical outcomes in patients with isolated type II superior labrum anterior posterior (SLAP) lesions.

Patients and methods: Thirty-eight patients (24 males, 14 females; mean age $53.2 \pm 6.6$ years; range, 45 to 67 years) who underwent arthroscopic treatment of type II SLAP lesions between June 2017 and September 2018 were evaluated prospectively. Visual analog scale (VAS), Simple Shoulder Test (SST), and American Shoulder and Elbow Surgeons (ASES) scores of all patients were recorded preoperatively, and at $6^{\text {th }}$ and $12^{\text {th }}$ months postoperatively. Biceps tenotomy was applied as arthroscopic surgical treatment in all patients. Biopsy materials obtained from rotator interval joint capsule and synovium during the arthroscopy were evaluated histopathologically. The density of the vessels in the specimens was defined as low, medium, and high by the pathologist. The patients with medium or low vessel density in specimens were group $1(\mathrm{n}=14)$ and those with high vessel density group $2(\mathrm{n}=24)$.

Results: In group 2, preoperative VAS score was significantly higher. There was no difference between the scores of the groups except for the sixth month SST score which was significantly higher in group 1. Histopathological evaluation revealed that the number of lymphocytes, fibroblasts, mast cells, myofibroblast, synovial lining cells, macrophages, and amount of collagen in connective tissue were significantly higher in group 2 . In five patients of group 2, the rehabilitation program was interrupted due to pain and difficulty in gaining a range of motion during the first four weeks postoperatively. Four of these patients recovered with medication and long-duration physiotherapy. Shoulder stiffness developed in one patient who required arthroscopic release and further rehabilitation.

Conclusion: There is a correlation between histopathological findings of joint capsule and synovium, and postoperative clinical outcomes and treatment in patients with isolated type II SLAP lesions. Almost 20\% of patients who had pathologic histological findings in joint capsule and synovium needed pain control and long-duration rehabilitation program after arthroscopic surgery for better shoulder function recovery and prevention of shoulder stiffness.

Keywords: Arthroscopy, histopathological evaluation, inflammation, injury, rehabilitation, superior labrum anterior posterior lesions. 
SLAP lesions. According to studies in the literature, $50-70 \%$ of patients with SLAP lesions were found to respond to nonoperative treatment with significant improvement in pain and function. Operative treatment was required in patients due to failure of nonoperative treatment. ${ }^{[4-6]}$ Operative treatment methods of SLAP lesions are labrum repair, biceps tenotomy, biceps tenodesis, or a combination of these treatments. After the operative treatment, returning to previous activity level, patient's satisfaction rate, and revision rate differ in various studies in the literature. ${ }^{[7,8]}$

It is recommended to consider the age, sex, functional requirements, the level of sporting activity, type of the lesion, and accompanying lesions in the treatment of SLAP lesions. ${ }^{[9,10]}$ Histological evaluation of the joint capsule and synovium has not been previously taken into consideration in treatment planning of patients with type II SLAP lesions. Accordingly, the hypothesis of this study is that pathologic histological changes in the joint capsule and synovium may complicate the progress of postoperative rehabilitation program and pain management. Inadequate pain management and physiotherapy could adversely affect treatment results of type IISLAP lesions. Therefore, in this study, we aimed to examine the joint capsule and synovium histologically to determine the correlation between histopathological findings and postoperative clinical outcomes in patients with isolated type II SLAP lesions.

\section{PATIENTS AND METHODS}

This prospective study included 38 patients (24 males, 14 females; mean age $53.2 \pm 6.6$ years; range, 45 to 67 years) with isolated SLAP II lesions who did not respond to nonoperative treatment and underwent arthroscopic management at the Ankara Numune Training and Research Hospital between June 2017 and September 2018. A written informed consent was obtained from each patient. The study protocol was approved by the Ankara Numune Training and Research Hospital Ethics Committee (No: E-17-1478, Date: July 12, 2017). The study was conducted in accordance with the principles of the Declaration of Helsinki.

Patients with previous shoulder and cervical region operations, rotator cuff tears requiring surgery, acromioclavicular joint degeneration, Bankart lesion, an extension of the labral tear into the anteriorinferior location, subacromial impingement requiring decompression and acromioplasty, other SLAP lesions, clinically frozen shoulder symptoms according to
Codman criteria (restricted elevation to $\leq 100^{\circ}$, passive external rotation $\leq 50 \%$ of the normal), and patients with a history of systemic inflammatory or metabolic disease that may affect soft tissues were excluded from the study. Patients treated only by biceps tenotomy for type II SLAP lesion were included. Patients treated with other methods were also excluded.

All patients were examined by the same operating orthopedic surgeon. Medical history and physical examination were performed in all patients. Visual analog scale (VAS), Simple Shoulder Test (SST), and American Shoulder and Elbow Surgeons (ASES) scores of all patients were recorded and all had shoulder radiograms and magnetic resonance imaging sections.

Shoulder function was evaluated with SST and ASES scores, and pain in the shoulder was evaluated with the VAS score. The evaluations were performed and documented preoperatively and at the $6^{\text {th }}$ and $12^{\text {th }}$ months by the same orthopedic surgeon.

The shoulder arthroscopies of the patients were performed on a beach chair position with standard portals. Isolated type II SLAP lesion diagnosis was confirmed by initial diagnostic arthroscopy. Biceps tendon was cut at biceps labral complex junction of the glenoid labrum. An arthroscopic radiofrequency device was used for this surgical intervention. Afterwards, labrum was debrided and fraying tissues were removed. Two biopsy samples nearly $2 \times 2 \mathrm{~mm}$ in dimensions including joint capsule and synovium were harvested from the rotator interval by arthroscopy punch. Biopsy samples were evaluated histopathologically, histochemically and immunohistochemically by the same pathologist. Pathologist evaluated the density of vessels, amount of collagen and quantity of lymphocytes, fibroblasts, mast cells, myofibroblasts, synovial lining cells, macrophages in the capsule and synovium.

We observed during arthroscopy that some patients had increased vascularity in the synovium while some had normal-appearing synovium in the rotator interval (Figure 1). Thinking that increased vascularity can be a predictor of pathologic changes, we grouped them according to the density of vessels in the biopsy specimens as group 1 (patients whose density of vessels were low or medium, $n=14$ ) and group 2 (patients whose density of vessels were high, $\mathrm{n}=24)$.

After the operation, an abduction sling was used for three weeks in all patients. Elbow, wrist, and hand range of motion (ROM) exercises were started in the immediate postoperative period. Scapular retraction 

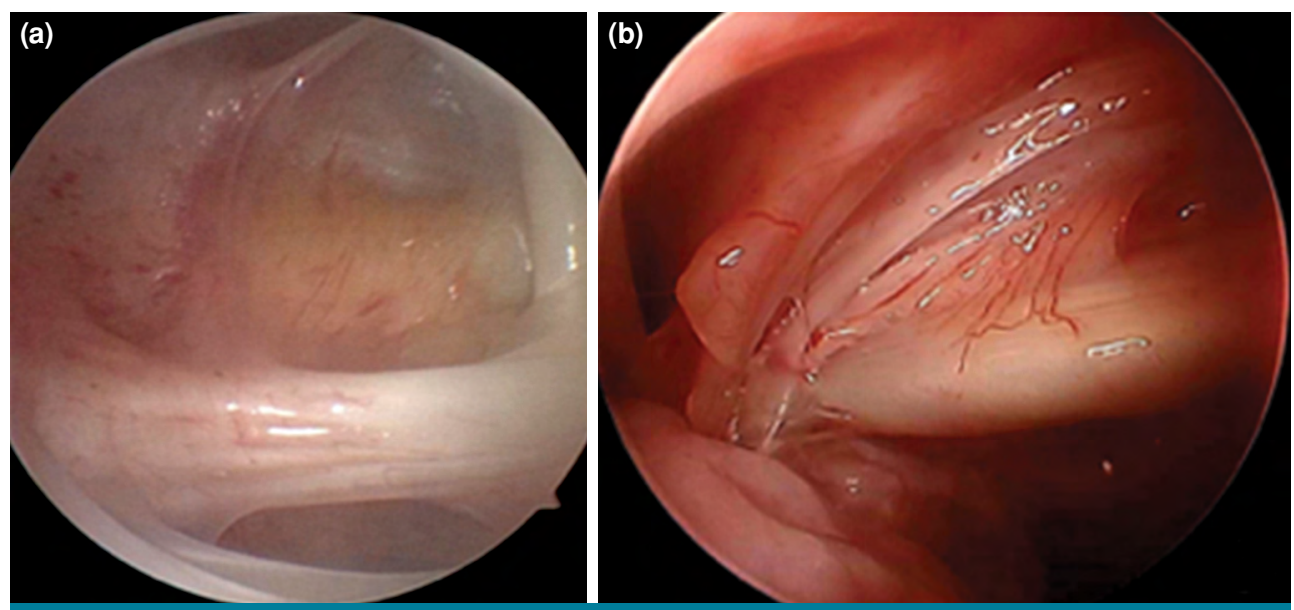

FIGURE 1. Arthroscopic view of joint synovium in rotator interval with (a) normal vascularity and (b) increased vascularity.

exercises were also started after the operation. At second-third weeks, gentle pendulum exercises and gentle shoulder active assistive ROM exercises were initiated. After the postoperative third week, active assistive $\mathrm{ROM}$ and isometric strengthening exercises were started under the supervision of the physiotherapists.
The biopsy materials were fixed in $10 \%$ buffered formalin and embedded in paraffin. The paraffin blocks were cut into $3 \mu \mathrm{m}$ sections and one slide of each case was stained with hematoxylin and eosin (H-E). Remaining slides were stained histochemically with toluidine blue and Masson's trichrome and smooth muscle actin (SMA), cluster
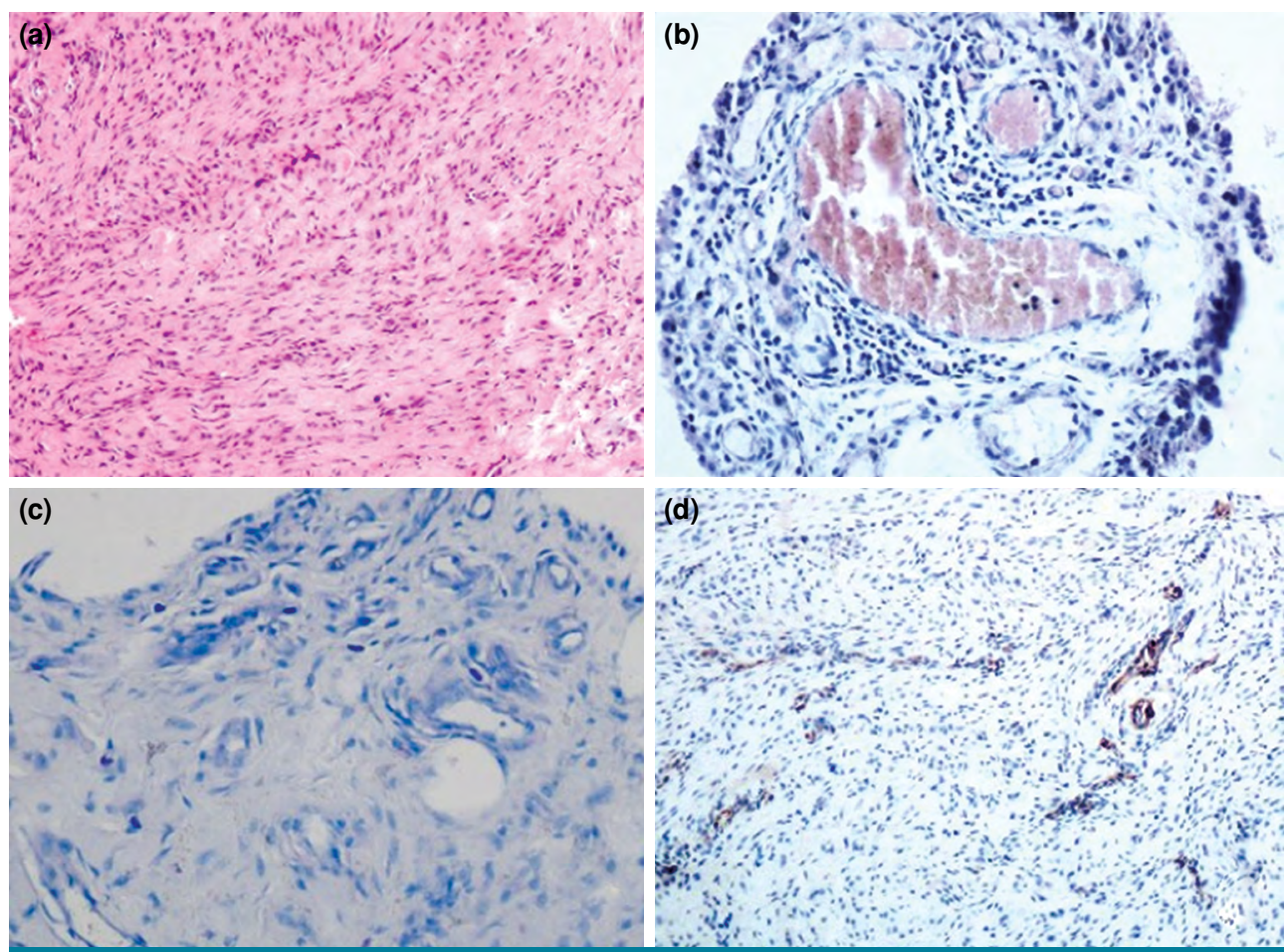

FIGURE 2. (a) Marked fibroblastic proliferation with little intervening collagenous stroma, hematoxylin and eosin $(H-E)$ staining $\times 200$. (b) Only a few cases showed groups of lymphoid cells in the $\mathrm{H}-\mathrm{E} \times 100$, (c) Mast cells in subsynovial connective tissue, toluidine blue $\times 400$, (d) The lack of SMA expression in proliferating mesenchymal cells indicates that these cells are not myofibroblasts but fibroblasts $\times 100$. 
of differentiation (CD) 68, and CD34 were performed immunohistochemically. All slides were evaluated by one pathologist blindly.

The number of cells was calculated in $1 \mathrm{~mm}^{2}$ area where they reached the highest density. Lymphocytes and fibroblasts were counted in H-E stained slides and toluidine blue stain revealed mast cells in the stroma. SMA was performed essentially to evaluate the myofibroblasts in this study, but it also stains the smooth muscle cells in the vessel walls (Figure 2). The vessel density was primarily assessed by using CD34, an endothelial marker, immunohistochemically (Figure 3). CD34 also stains hematopoietic progenitor cells and some mesenchymal cells. In our study we observed that pre-existing subsynovial mesenchymal cells but not proliferating fibroblasts express CD34 as well. CD68 identified synovial lining cells and macrophages in subsynovial stroma (Figure 4).

The amount of collagen was evaluated in Masson trichrome stain and graded by using the semiquantitative scale: grade 1: little amount of collagen, grade 2: moderate amount of collagen, and grade 3: dense collagen.

The immunohistochemical (IHC) staining was performed in an automated staining system (Leica Bond Max, Leica Biosystems, Newcastle, United Kingdom) using optimized IHC parameters. The sections were baked and dewaxed in the Leica system.

All antibodies were detected with the Leica Bond Polymer detection kit (DS9800 Leica Biosystems, Newcastle, United Kingdom), including diaminobenzidine reaction to detect the antibody labeling and hematoxylin counterstaining. Negative and positive controls were used as recommended by the manufacturer.

\section{Statistical analysis}

Statistical analyses were performed using the IBM SPSS statistics 22.0 software (IBM Corp., Armonk, NY, USA). Descriptive statistics for the numerical variables were expressed as the mean \pm standard deviation (SD).

In the normality analysis, nonparametric test procedures were performed since the values did not show normal distribution using the Shapiro-Wilk test. The Mann-Whitney U test, a nonparametric alternative to the two-sample independent t-test, was used to determine the relationships between parameters. In the analysis of categorical data, chisquare test was used. The results were evaluated
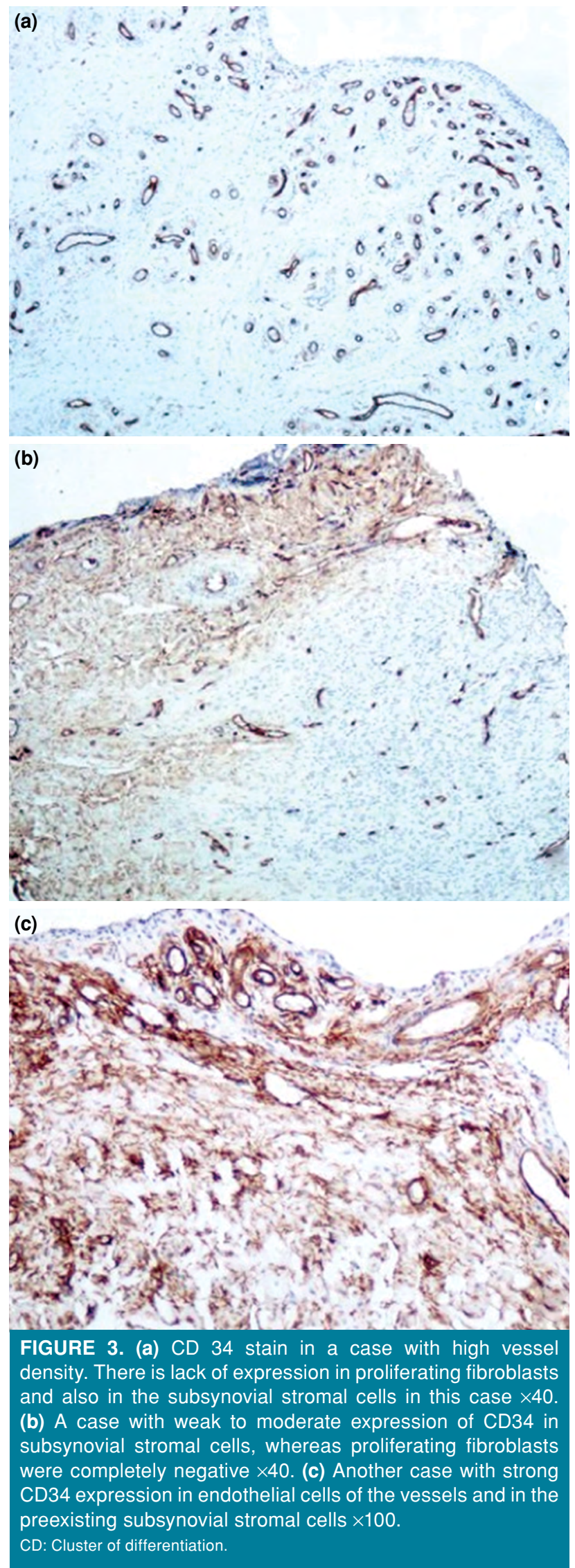


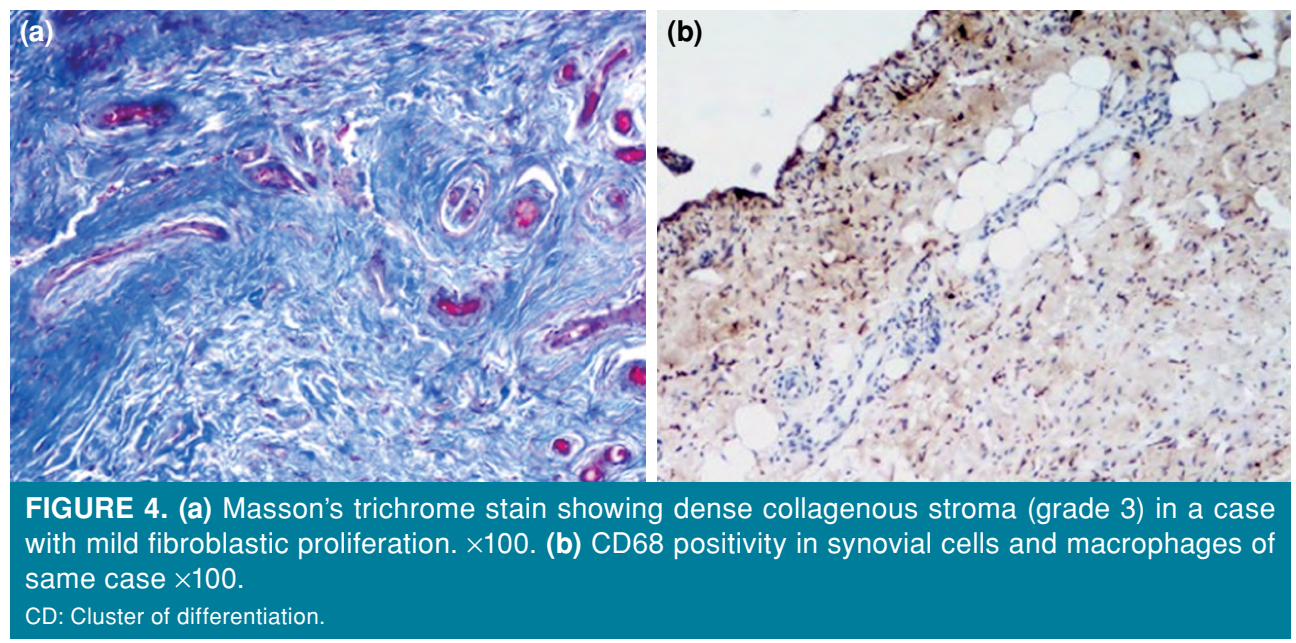

within the $95 \%$ confidence interval and $\mathrm{p}<0.05$ was considered as statistically significant.

\section{RESULTS}

The demographic values of groups 1 and 2 were compared (Table I). The mean age of the patients was $50.1 \pm 5.5$ years in group 1 and $55.0 \pm 6.6$ years in group 2. None of the patients included in the study were professional athletes or overhead athletes. The distribution of the density of vessels was shown in Table II. The pre- and postoperative $6^{\text {th }}$ and $12^{\text {th }}$ month VAS, SST, and ASES scores were given in Table III.

The preoperative VAS score was significantly higher in group $2(\mathrm{p}=0.043)$. In both groups, VAS scores improved from preoperative score compared with $12^{\text {th }}$ month follow-up. In group 1 , mean VAS score improved by 7.4 points, from 7.7 to 0.3 points. In

\begin{tabular}{|c|c|c|c|c|c|}
\hline & De & $\begin{array}{l}\text { TABLE } \\
\text { graphic dat }\end{array}$ & of $p e$ & ients & \\
\hline & Gr & $p 1(n=14)$ & Gro & $p 2(n=24)$ & \\
\hline & $\mathrm{n}$ & Mean $\pm S D$ & $n$ & Mean $\pm S D$ & $p$ \\
\hline Age (year) & & $50.1 \pm 5.5$ & & $55.0 \pm 6.6$ & $0.014^{*}$ \\
\hline Side & & & & & 0.357 \\
\hline Right & 6 & & 14 & & \\
\hline Left & 8 & & 10 & & \\
\hline ASA score & & $1.6 \pm 0.5$ & & $1.9 \pm 0.6$ & 0.052 \\
\hline Sex & & & & & 0.132 \\
\hline Male & 11 & & 13 & & \\
\hline Female & 3 & & 11 & & \\
\hline
\end{tabular}

group 2, mean VAS score improved by 7.7 points, from 8.4 to 0.7 points. There was no statistically significant difference in postoperative $6^{\text {th }}$ and $12^{\text {th }}$ month VAS score between the groups (Table III, Figure 5).

In both groups, functional outcomes (ASES and SST) were improved from preoperative score compared with $12^{\text {th }}$ month follow-up. Mean ASES score improved by 73.5 points, from 16.5 to 90 points in group 1 , and by 71.5 points, from 16 to 87.5 points in group 2. Mean SST score improved by 7.5 points, from 2.9 to 10.4 points in group 1 and by 7.4 points, from 2.6 to 10 points in group 2 . There was no statistically significant difference in preoperative SST and ASES scores and postoperative $12^{\text {th }}$ month SST and ASES scores between the groups (Table III, Figures 6 and 7).

Histopathological evaluation revealed that lymphocytes, fibroblasts, mast cells, myofibroblast, synovial lining cells, macrophages, and amount of collagen were significantly higher in group 2 $(p<0.05)$ (Tables IV and V). We accepted the increased inflammatory cell count, synovial cell count, increased amount of collagen, and vascularity as pathologic histological findings in the joint capsule and synovium in group 2.

\section{TABLE II}

Distribution of patients according to CD34 (vessel density)

\begin{tabular}{|c|c|c|c|}
\hline & Low & Medium & High \\
\hline & $\mathrm{n}$ & $\mathrm{n}$ & $\mathrm{n}$ \\
\hline \multicolumn{4}{|l|}{ CD34 } \\
\hline Group $1(n=14)$ & 12 & 2 & \\
\hline Group $2(n=24)$ & & & 24 \\
\hline
\end{tabular}




\begin{tabular}{|c|c|c|c|c|}
\hline \multicolumn{5}{|c|}{$\begin{array}{l}\text { TABLE III } \\
\text { Comparison of pre- and postoperative test results }\end{array}$} \\
\hline & & Group 1 ( $n=14)$ & Group $2(n=24)$ & \multirow[b]{2}{*}{$p$} \\
\hline & & Mean \pm SD & Mean $\pm S D$ & \\
\hline \multirow[t]{3}{*}{ Preoperative } & VAS & $7.7 \pm 1.0$ & $8.4 \pm 1.1$ & $0.043^{*}$ \\
\hline & SST & $2.9 \pm 0.9$ & $2.6 \pm 1.4$ & 0.441 \\
\hline & ASES & $16.5 \pm 7.0$ & $16.0 \pm 12.0$ & 0.377 \\
\hline \multirow[t]{3}{*}{ Postoperative $6^{\text {th }}$ month } & VAS & $0.8 \pm 1.1$ & $1.1 \pm 2.0$ & 0.731 \\
\hline & SST & $8.9 \pm 0.6$ & $8.2 \pm 0.9$ & $0.008^{*}$ \\
\hline & ASES & $85.4 \pm 3.9$ & $83.2 \pm 11.9$ & 0.493 \\
\hline \multirow[t]{3}{*}{ Postoperative $12^{\text {th }}$ month } & VAS & $0.3 \pm 0.5$ & $0.7 \pm 2.1$ & 0.849 \\
\hline & SST & $10.4 \pm 0.5$ & $10.0 \pm 0.9$ & 0.117 \\
\hline & ASES & $90.1 \pm 4.4$ & $87.6 \pm 13.2$ & 0.951 \\
\hline
\end{tabular}

All patients in group 1 and 19 patients in group 2 were able to finalize the planned rehabilitation program. In five patients in group 2, physiotherapy had to be interrupted at postoperative third-fourth weeks due to severe pain. These patients received intraarticular corticosteroid injection, antiinflammatory medication, and immobilization therapy. After about a week of pain control, these patients could be re-rehabilitated. The active ROM and isometric strengthening phase of rehabilitation were achieved by a meticulous and long-duration rehabilitation program. The home rehabilitation program was applied from the $12^{\text {th }}$ week to the sixth month.

Shoulder stiffness developed in one patient in group 2 (4.1\%). In this patient, algologist performed intraarticular injections of combined analgesics and corticosteroids. Also, ROM exercises were performed

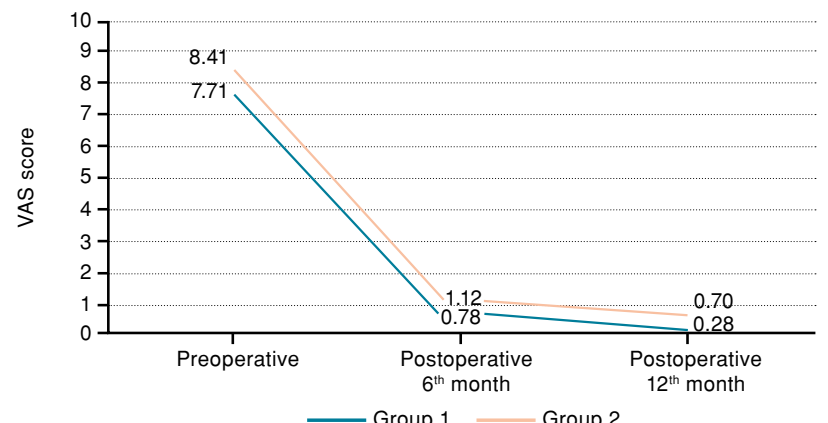

FIGURE 5. Preoperative, postoperative sixth month, and postoperative $12^{\text {th }}$ month visual analog scale scores of study groups.

VAS: Visual analog scale.

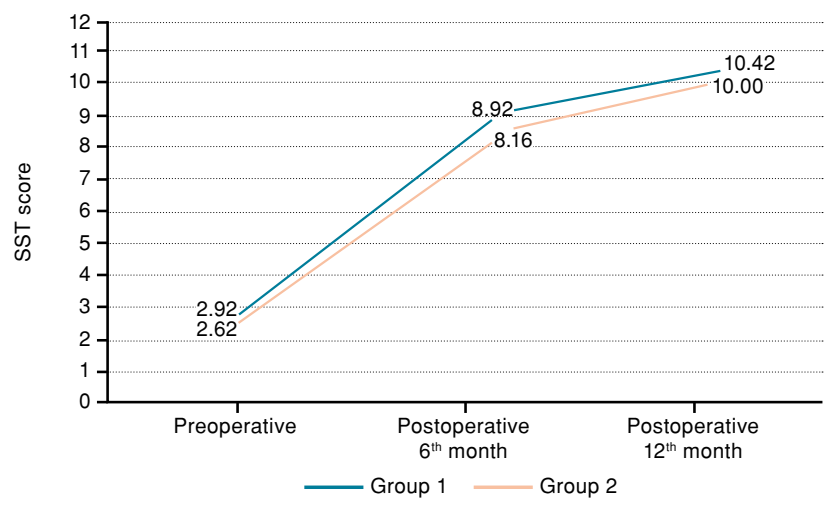

FIGURE 6. Preoperative, postoperative sixth month, and postoperative $12^{\text {th }}$ month Simple Shoulder Test scores of study groups.

SST: Simple Shoulder Test.

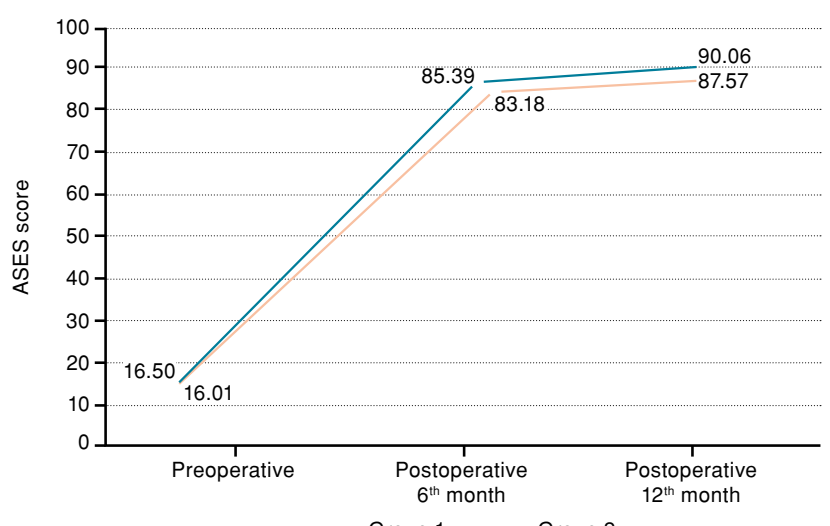

FIGURE 7. Preoperative, postoperative sixth month, and postoperative $12^{\text {th }}$ month American Shoulder and Elbow Surgeons scores of study groups.

ASES: American Shoulder and Elbow Surgeons. 


\begin{tabular}{|c|c|c|c|}
\hline \multicolumn{4}{|c|}{$\begin{array}{r}\text { TABLE IV } \\
\text { Comparison of amount of collagen }\end{array}$} \\
\hline & $\begin{array}{c}\text { Group } 1 \\
(n=14)\end{array}$ & $\begin{array}{c}\text { Group } 2 \\
(n=24)\end{array}$ & \\
\hline & $\mathrm{n}$ & $\mathrm{n}$ & $p^{*}$ \\
\hline \multicolumn{4}{|c|}{ Amount of collagen } \\
\hline Little & 12 & 5 & \\
\hline Moderate & 2 & 10 & 0.000 \\
\hline Dense & & 9 & \\
\hline
\end{tabular}

with manual therapy by a physiotherapist. However, the patient did not respond to pain treatment and physiotherapy. At the postoperative sixth month, arthroscopic rotator interval release and coracoplasty were applied due to shoulder stiffness. Complete improvement was observed in this patient by applying various physiotherapy modalities for up to six months.

\section{DISCUSSION}

The most important finding of this study is that if patients with type II SLAP lesions also have pathologic histological changes in the synovium and capsule, they may have difficulty in gaining ROM and pain relief during the postoperative rehabilitation period. In our opinion, this group of patients has two pathologies that need to be treated simultaneously: the type II SLAP lesion and the pathologic histological changes in the synovium and joint capsule.

Nonoperative treatment is often proposed initially in patients with SLAP lesions. According to the literature, significant improvements in pain, function, and quality of life are achieved in 50-70\% of patients with nonoperative management. ${ }^{[4,5]}$

Operative treatment is proposed for patients in whom pain relief and return to previous level of activity cannot be attained with nonoperative treatment. Various methods including arthroscopic SLAP repair, SLAP repair and biceps tenodesis, or only biceps tenotomy has been used in the surgical treatment of these injuries. Successful treatment results, patient satisfaction rate, and return to previous level of activity vary in publications in the literature. Gorantla et al., ${ }^{[11]}$ in their systemic review including 12 studies, concluded that after type II SLAP repair, the percentage of good and excellent results ranged from 40 to $94 \%$. Return to previous level of play ranged from 20 to $94 \%$. Provencher et al. ${ }^{[8]}$ evaluated the results of 179 patients with type II SLAP lesions who had arthroscopic SLAP repair. In their series, return to the previous activity level was limited: $37 \%$ of patients had a failure, with a 28\% revision rate. Age greater than 36 years was associated with a higher chance of failure. ${ }^{[8]}$ Tenodesis is generally recommended to treat SLAP lesions with obvious associated biceps pathology including partial tears of the biceps tendon and macroscopic evidence of tendinosis. ${ }^{[12]}$ Boileau et al. ${ }^{[7]}$ compared outcomes of biceps tenodesis with SLAP repair in 25 patients. They concluded that in the repair group, $40 \%$ of the patients were satisfied, and $20 \%$ of them were able to return to their previous level of sports participation. In the tenodesis group, 93\% of the patients were satisfied and $87 \%$ returned to their previous level of sports participation. Biceps tenotomy is generally considered for older, sedentary patients with less need for functional biceps strength. In the literature, studies about clinical results of isolated biceps tenotomy in the treatment of type II SLAP lesions are limited. Ren et al. ${ }^{[13]}$ assessed eight studies in their metaanalysis. They concluded that arthroscopic biceps tenotomy and tenodesis treatment provides better clinical outcome in ASES score and satisfaction rate and comparable complications compared with arthroscopic repair treatment. According to these studies, we may claim that patients with type II SLAP lesions may not have significant improvements in pain, function, and quality of life after operative treatment although different surgical methods are used for the patient.

Our hypothesis was that the presence of histopathological changes in joint synovium and capsule could affect final results of operative treatment

\begin{tabular}{|c|c|c|c|c|c|}
\hline \multicolumn{6}{|c|}{$\begin{array}{l}\text { Comparison of inflammation, vascular proliferation, fibroblast proliferation, CD68 } \\
\text { (synovial lining cell), and mast cells between study groups }\end{array}$} \\
\hline & INF & VP & FP & CD68 & MAST \\
\hline Mann-Whitney U & 31,000 & 83,000 & 25,000 & 54,000 & 64,500 \\
\hline$p^{*}$ & 0.000 & 0.010 & 0.000 & 0.001 & 0.002 \\
\hline
\end{tabular}


by complicating rehabilitation program and pain control in the postoperative period.

Normal synovial tissue is characterized by a surface layer of cells, below a loose connective tissue which contains fibroblasts, macrophages, adipocytes, mast cells, nerve fibers, vascular endothelial cells, polymorphs and lymphocytes. ${ }^{[14]}$ Wechalekar and Smith ${ }^{[15]}$ state that inflammatory diseases are characterized by thickening of the synovial lining, macrophage recruitment, fibroblast proliferation, and an influx of inflammatory cells including lymphocytes, monocytes and plasma cells. In the present study, the histopathological findings of group 2 are in accordance with the study of Wechalekar and Smith. ${ }^{15]}$ Indicating that inflammated synovium and capsule may cause pain and restrict joint movements as in the inflammatory diseases.

In our study, all patients in group 1 completed the planned rehabilitation program. In group 2, rehabilitation programs of five patients were interrupted due to pain and trouble in performing ROM exercises. Meticulous, gentle, and longduration rehabilitation programs with various physical therapy modalities were applied under the supervision of experienced physiotherapists. Antiinflammatory and analgesic treatment was regulated by an algologist. With this customized physiotherapy, four patients recovered in three months. However, one patient had arthroscopic release and coracoplasty at sixth month for treatment of shoulder stiffness. In the $12^{\text {th }}$ month control, ASES, VAS, and SST scores were similar in groups 1 and 2 .

Increased vascularity in the synovium of the rotator interval is macroscopically visible and could be observed during artroscopic surgery (Figure 1). All patients with high vessel density had histopathological findings in the synovium and capsule (group 2). Five of the 24 patients in this group had trouble in gaining $\mathrm{ROM}$ and pain relief during postoperative rehabilitation period. Customized and long-duration physiotherapy was required for recovery. We think that the increased vascularity in the synovium of the rotator interval is an important arthroscopic finding that has to be considered in the regulation of the postoperative rehabilitation program. We recommend taking biopsy from synovium and joint capsule for histological evaluation if the surgeon is doubtful about the vascular density of the synovium during arthroscopic surgery.

The limitations of this study were the low number of patients, the evaluation of patients treated with only biceps tenotomy, and their implementation in a single center. The power of this study is histopathological evaluation of the shoulder joint capsule and synovium in patients with type II SLAP lesion. To the best of our knowledge, this is the first study mentioning the effect of pathologic histological changes in the joint synovium and capsule on the treatment outcomes.

In conclusion, there is a correlation between histopathological findings of joint capsule and synovium, and postoperative clinical outcomes and treatment in patients with isolated type II SLAP lesions. These patients need anti-inflammatory and analgesic treatment for pain control and longduration customized rehabilitation program after arthroscopic surgery for better shoulder function recovery and prevention of shoulder stiffness.

\section{Declaration of conflicting interests}

The authors declared no conflicts of interest with respect to the authorship and/or publication of this article.

\section{Funding}

The authors received no financial support for the research and/or authorship of this article.

\section{REFERENCES}

1. Özer M, Ataoğlu MB, Çetinkaya M, Ayanoğlu T, Kaptan AY, Kanatlı U. Do intra-articular pathologies accompanying symptomatic acromioclavicular joint degeneration vary across age groups? Eklem Hastalik Cerrahisi 2019;30:2-9.

2. Ek ET, Shi LL, Tompson JD, Freehill MT, Warner JJ. Surgical treatment of isolated type II superior labrum anteriorposterior (SLAP) lesions: repair versus biceps tenodesis. J Shoulder Elbow Surg 2014;23:1059-65.

3. Hester WA, O'Brien MJ, Heard WMR, Savoie FH. Current concepts in the evaluation and management of type II superior labral lesions of the shoulder. Open Orthop J 2018;12:331-41.

4. Jang SH, Seo JG, Jang HS, Jung JE, Kim JG. Predictive factors associated with failure of nonoperative treatment of superior labrum anterior-posterior tears. J Shoulder Elbow Surg 2016;25:428-34.

5. Edwards SL, Lee JA, Bell JE, Packer JD, Ahmad CS, Levine $\mathrm{WN}$, et al. Nonoperative treatment of superior labrum anterior posterior tears: improvements in pain, function, and quality of life. Am J Sports Med 2010;38:1456-61.

6. Hashiguchi H, Iwashita S, Yoneda M, Takai S. Factors influencing outcomes of nonsurgical treatment for baseball players with SLAP lesion. Asia Pac J Sports Med Arthrosc Rehabil Technol 2018;14:6-9.

7. Boileau P, Parratte S, Chuinard C, Roussanne Y, Shia D, Bicknell R. Arthroscopic treatment of isolated type II SLAP lesions: biceps tenodesis as an alternative to reinsertion. Am J Sports Med 2009;37:929-36.

8. Provencher MT, McCormick F, Dewing C, McIntire S, Solomon D. A prospective analysis of 179 type 2 superior labrum anterior and posterior repairs: outcomes and factors associated with success and failure. Am J Sports Med 2013;41:880-6. 
9. Stathellis A, Brilakis E, Georgoulis JD, Antonogiannakis E, Georgoulis A. Treatment of SLAP lesions. Open Orthop J 2018;12:288-94.

10. Brockmeyer M, Tompkins M, Kohn DM, Lorbach O. SLAP lesions: a treatment algorithm. Knee Surg Sports Traumatol Arthrosc 2016;24:447-55.

11. Gorantla K, Gill C, Wright RW. The outcome of type II SLAP repair: a systematic review. Arthroscopy 2010;26:537-45.

12. Sullivan S, Hutchinson ID, Curry EJ, Marinko L, Li X. Surgical management of type II superior labrum anterior posterior (SLAP) lesions: a review of outcomes and prognostic indicators. Phys Sportsmed 2019;47:375-86.

13. Ren YM, Duan $Y H$, Sun $Y B$, Yang $T$, Hou WY, Tian MQ. Is arthroscopic repair superior to biceps tenotomy and tenodesis for type II SLAP lesions? A meta-analysis of RCTs and observational studies. J Orthop Surg Res 2019;14:48.

14. FitzGerald O, Bresnihan B. Synovial membrane cellularity and vascularity. Ann Rheum Dis 1995;54:511-5.

15. Wechalekar MD, Smith MD. Utility of arthroscopic guided synovial biopsy in understanding synovial tissue pathology in health and disease states. World J Orthop 2014;5:566-73. 